\title{
Lipodystrophic Syndrome in Children and Adolescents Infected With the Human Immunodeficiency Virus
}

\author{
Crésio Alves, Ana Cláudia Oliveira and Carlos Brites \\ School of Medicine, Federal University of Bahia; Salvador, BA, Brazil
}

\begin{abstract}
The introduction of highly active antiretroviral therapy (HAART) for the treatment of acquired immunodeficiency syndrome (AIDS) has resulted in greater survival of patients infected with the human immunodeficiency virus (HIV). However, the use of these drugs has been associated with lipodystrophic syndrome (LS), which is characterized by metabolic alterations (dyslipidemia, insulin resistance, diabetes, and lactic acidosis) and abnormal corporal fat distribution. Clinically, LS may manifest as three different forms: lipohipertrophy (accumulation of fat in the central part of the body), lipoatrophy (loss of fat in the extremities, face and buttocks) and mixed (lipohipertrophy + lipoatrophy). Although its physiopathology has not been elucidated, some mechanisms have been described, including leptin and adiponectin deficiency, mitochondrial dysfunction and use of antiretroviral drugs. The type, dose and duration of the antiretroviral treatment, as well as age and puberty are the main risk factors. LS is also associated with increased incidence of cardiovascular illnesses, atherosclerosis and diabetes mellitus. Treatment includes physical activity, cautious restriction of caloric intake, changes in antiretroviral therapy, and use of insulin-sensitizing and lipid-lowering agents. Follow up must be periodic, consisting of measurement of body fat distribution, evaluation of the lipid profile and insulin resistance.
\end{abstract}

Key-Words: HIV, lipodystrophy, highly active antiretroviral treatment, children and adolescents.

The first report about childhood-acquired immunodeficiency syndrome (AIDS) was described in 1982 [1]. Since then, the increase in heterosexual transmission has resulted in a higher incidence of cases among women and a consequent increase in vertical transmission. About 75\%-85\% of infected children acquire human immunodeficiency virus (HIV) through this pathway; 20\%-25\% through blood transfusion or blood products; in older children and adolescents, HIV is acquired through sexual transmission or use an intravenous drug needles [1-2]. In 2000, Szwarcwald et al. estimated that 12,800 children 0 -14 years-old were infected by HIV in Brazil and that 1,968 were born alive with HIV [3].

The introduction of highly active antiretroviral therapy (HAART) modified the natural history of HIV infection, decreasing the mortality and progression of this disease. Nevertheless, it has become clear that this therapy provokes metabolic disorders (such as dyslipidemia, insulin resistance, and lactic acidosis) and body fat redistribution, a condition known as lipodystrophic syndrome (LS). This syndrome is of great concern for vertically HIV-infected children, as they are exposed to HAART and its long-term side effects for a long period. The undefined prevalence of LS is due to a lack of a consensual definition [7, 9]. Recent studies estimate a 25-30 percent prevalence rate among the pediatric HIV-infected population [9].

We reviewed current knowledge about LS associated with HIV in the pediatric population, focusing on its epidemiology, clinical presentation, pathophysiology and treatment.

Received on 5 April 2008; revised 2 July 2008.

Address for correspondence: Dr. Crésio Alves. Rua Plínio Moscoso, No. 222, Apto. 601. Zip code: 40157-190. Salvador - Bahia - Brasil.

Telefone: (55) (71) 9178-4055. E-mail: cresio.alves@uol.com.br.

The Brazilian Journal of Infectious Diseases 2008;12(4):342-348. (C) 2008 by The Brazilian Journal of Infectious Diseases and Contexto Publishing. All rights reserved.

\section{Risk Factors for Lipodystrophic Syndrome}

The most widely studied risk factors for LS are: antiretroviral therapy, age and gender [10].

\section{Antiretroviral Drugs}

Each of the classes of antiretroviral drugs (nucleotide reverse transcriptase inhibitors [NRTI], non-nucleoside reverse transcriptase inhibitors [NNRTI] and protease inhibitors [PI]), has been associated with LS, although the strongest association is with PIs [10-13]. The longer the exposure to these drugs, the worse the severity and progression of LS [14-15]. Among children with LS, 39\% of those treated for more than six years presented four or more signs of lipodystrophy, compared with the $14 \%$ of those with less than three years of treatment [9]. The average time till detection of dyslipidemia and of signs of body fat redistribution after antiretroviral therapy was instituted, ranged from 7.1 to 31.7 months [5]. Children who received a pediatric dosage had a lesser likelihood of developing LS, when compared with those who received an adult dosage [16].

\section{Age and Gender}

Adolescents present a more severe lipodystrophy clinical picture, while prepubertal children express a milder clinical presentation [5,7,17-19]. This could be due to hormonal changes during puberty [5]. There has been concern about how gender affects susceptibility to these syndromes. The European Paediatric Lipodystrophy Group concluded that there is a higher risk of girls developing lipodystrophy [9]; however, in Werner's study there were no differences in prevalence between genders [20].

\section{Components of Lipodystrophic Syndrome}

The two main components of LS are body fat redistribution and metabolic syndrome. 


\section{Body Fat Redistribution}

Therapy with PI and NRTI is the main factor associated with body fat redistribution disorder [6]. Recent studies have shown that central body fat accumulates in patients that have not been exposed to antiretroviral therapy, which demonstrates that such alterations can be due both to HIV infection and to the use of these drugs [21].

Clinically there are three patterns of body fat redistribution: (1) lipoatrophy: localized fat loss in the limbs, face and buttocks; (2) lipohypertrophy: central fat accumulation in the trunk, abdomen and posterior neck (buffalo hump); and (3) mixed pattern (lipoatrophy plus lipohypertrophy) [22]. Another sign that can be present is breast enlargement, both in men and in women [23].

Although lipoatrophy is the most characteristic type of LS in adults, there is no consensus on its being the most common clinical presentation in the pediatric-age group [6]. Vigano et al. described the mixed pattern as being the most frequent [24]. Torres et al. found that among children on antiretroviral drugs, $12.5 \%$ presented lipohypertrophy, $3.5 \%$ lipoatrophy and $8.9 \%$ a mixed pattern [7]. Jaquet et al. reported that $20.5 \%$ of the children had lipohypertrophy, 7.7\% lipoatrophy and 5.1\% combined lipodystrophy [18]. The "European Paediatric Lipodystrophy Group" (2004) reported that $66 \%$ of the children had fat accumulation in the trunk, $40 \%$ had fat loss in the lower limbs, 39\% had facial lipoatrophy, $37 \%$ had fat loss in the upper limbs, $22 \%$ had fat loss in the buttocks, 18\% had buffalo hump and 4\% had breast enlargement [9]. In Brazil, Werner found a 17.4 percent prevalence rate of lipodystrophic syndrome, characterized mainly by the lipoatrophic type among children and adolescents [20]. The lack of standardized diagnostic criteria for dystrophic alterations and the difficulty in differentiating them from normal physical developmental changes of childhood have contributed to the difficulty in classifying the distinct types of lipodystrophy [16,25].

As anthropometry alone does not allow precise characterization of these changes, alternate diagnostic tools have been used to improve the evaluation of the distribution of body fat [26]. DEXA (dual energy X-ray absortiometry) is considered the gold standard for the study of fat composition and distribution in children, while computed tomography and magnetic resonance imaging are indicated for detecting abdominal fat [26]. However, high cost, the need for sedation and absence of reference values limit the use of these methods [5,25,27]. Consequently, in medical practice clinical presentation remains the most widely-used criterion, even though it is known that the lipodystrophy prevalence rate can be underestimated [5].

\section{Metabolic Syndrome}

The main metabolic disorders presented in LS are dyslipidemia, insulin resistance and lactic acidosis.

\section{Dyslipidemia}

Dyslipidemia can be an isolated disorder or part of LS [6]. Usually, it is of the mixed type, characterized by a decrease in HDL (high density lipoprotein) and increases in total cholesterol, LDL cholesterol (low density lipoprotein) and triglycerides (TG). According to the "European Paediatric Lipodystrophy Group" (2004), 51\% of children with LS presented dyslipidemia, 37\% with hypercholesterolemia and $34 \%$ with hypertriglyceridemia [9]. In Brazil, Werner reported a $86 \%$ prevalence rate of dyslipidemia in a sample of children and adolescents with HIV [20].

Although dyslipidemia can occur in children not treated with antiretroviral drugs, its usage, especially the PIs, favors the development of dyslipidemia [6,27-28]. Among the PIs, ritonavir is the most commonly associated with dyslipidemia [29].

\section{Insulin Resistance}

Hyperinsulinemia and insulin resistance can occur as a result of therapy with PI or as a consequence of the HIV infection [22,30]. Initially, it was believed that the PI do not influence carbohydrate metabolism in prepubertal children, due to the higher insulin sensitivity observed in this phase [17]. Nonetheless, recent studies have shown that these drugs lead to insulin resistance, both by decreasing the pancreatic beta cell response and through interference of the glucose transportation promoted by GLUT-4 (insulin-regulated transmembrane glucose transporter) transport protein [6,31]. Therefore, treatment of HIV-infected children with PI leads to the development of insulin resistance, similar to what has been observed in adults. The difference is in the difficulty in detecting this alteration [31].

Besides glucose intolerance and diabetes, insulin resistance can cause hypertriglyceridemia, activation of the sympathetic nervous system, with sodium retention, and increased risk of cardiovascular disease [32-33]. The gold standard for diagnosing insulin resistance is the euglycemic clamp test. However, simpler procedures can be used, such as fasting glucose, insulin and C-peptide measurement, HOMA (homeostasis model assessment) index calculation and OGTT (oral glucose tolerance test) [6,31].

\section{Lactic Acidosis}

The first report about lactic acidosis in HIV patients is from 1990. In the classical presentation (1.3-1.7/1,000 persons year), the patients develop a sudden onset of nausea, vomiting, abdominal pain, fatigue, tachycardia, dyspnea on exertion, weight loss, hepatic steatosis, and rarely, hepatic failure [6]. The milder clinical presentation (26/1,000 persons year), so-called asymptomatic hyperlactatemia, does not present any symptom at all [6].

Both conditions, lactic acidosis and hyperlactatemia, are induced by NRTI therapy. Probably this is a result of mitochondrial DNA inhibition, as adult patients treated with these drugs present ultrastructural and functional defects in the mitochondria $[6,12,34]$. 
Asymptomatic hyperlactemia was diagnosed in $32 \%$ of the children submitted to HAART (both PI and NRTI) in an undetectable HIV viral load study [35]. In this setting, hyperlactemia can be a compliance marker for therapy, showing that elevated lactic acid serum levels do not mean lactic acidosis with hepatic dysfunction or death risk. Also, follow-up of the lactate serum levels can differentiate viral resistance from noncompliance through viral load relapse [35].

\section{Cardiovascular Manifestations}

The main risk factors involved in the development of atherosclerotic cardiovascular disease in HIV-infected patients are dyslipidemia, body fat redistribution, insulin resistance, vascular inflammation, fibrinolysis disorder and the side effects of antiretroviral therapy [36-38]. Their association with the traditional risk factors increases the risk of precocious atherosclerotic disease. The higher risk for precocious atherosclerotic disease in pediatric patients seems to be related to dyslipidemia [6].

The contribution of body fat redistribution to the risk of cardiovascular disease is unknown [6]. Patients with lipodistrophy usually present central obesity, associated with increased visceral fat, insulin resistance and dyslipidemia, which are risk factors for cardiovascular disease [6]. However, lipodistrophy has not been significantly associated with risk for myocardial infarction [39]. Other studies have reported an increase of coronary artery disease risk in patients without lipodistrophy, implying that the infection itself is involved in the development of this pathology [6].

The connection between cardiovascular disease and HAART is not well defined [39-40]. Mary-Krause et al. showed that myocardial infarction risk increased with PI usage [41]. On the other hand, Bozzette et al. found that hospital admission due to cardiovascular and cerebrovascular disease was reduced after HAART, reaffirming the importance of this treatment for the survival of these patients [42]. This suggests that the extended life expectancy ascribed to HAART overlaps its association with cardiovascular events [41]. Though some studies have demonstrated that zidovudine is toxic for cardiac cell mitochondria, other researchers have not found evidence of this relationship [43]. Children exposed to zidovudine during the perinatal period and followed until 14 months old did not have a higher likelihood to develop abnormalities in the structure and function of the left ventricle, suggesting that the benefits from using zidovudine during pregnancy for the prevention of HIV vertical transmission are greater than the cardiac risks to the children [43].

\section{Pathophysiology of the Lipodystrophic Syndrome}

The pathophysiology of LS associated with HAART is little known. The best studied mechanisms are changes in cellular expression of CRABP-1 (cellular retinoic acid-binding protein 1) and LRP (low density lipoprotein receptor-related protein), SREBP-1c (steroid regulatory element binding protein-1c) disorders, interference in GLUT-4, alteration of serum levels of leptin and adiponectin, and mitochondrial dysfunction.

\section{CRABP-1 an LRP}

Carr et al. have shown that the PI binding site of viral proteins is structurally similar to that of some lipid metabolism proteins (CRABP-1 and LRP) [4]. Thus, PI usage would lead to partial or total inhibition of this type of metabolism. Other mechanisms through which PI cause dyslipidemia are inhibition of the activity of serum lipoprotein-lipase with lipolytic activity inhibition and increased serum triglycerides, and competition for the binding site of hepatic receptors of the chylomicronremnant, due to molecular similarity. Modifications in the lipid profile of HIV carriers after the institution of PI reflect mainly its interference in the exogenous pathway of lipid metabolism [44].

\section{GLUT-4}

The use of PI and NRTI has been associated with insulin resistance, through inhibition of muscular and adipocyte GLUT-4, decreasing glucose intake mediated by insulin in these tissues [6]. This effect is more evident when the patient is on ritonavir and less evident when he is being treated with atazanavir [45].

\section{SREBP-1C}

SREBP-1c is a transcription factor regulated by insulin, whose function is to activate lipogenic-enzyme genes. It is decreased in LS. It was suggested that the various alleles that code for SREBP-1c, a polymorphic gene, are responsible for the clinical manifestation spectrum of LS [13]. The PI inhibit adipogenesis and adipocyte differentiation and modify the intracellular localization of SREBP-1c [13,46]. The adjustments of SREBP- 1 cause defective expression of PPAR- $\gamma$ (peroxisome proliferator-activated receptor gamma) interfering in glucose metabolism [46].

\section{Leptin and Adiponectin}

Leptin is a cytokine associated with the immune system. Its levels are enhanced in lipodystrophic syndrome patients, especially those with lipohypertrophy. However, its levels are reduced in patients with generalized lipodystrophy. Restoring the leptin levels leads to homeostasis of body fat distribution, glycemia, dyslipidemia and hepatic steatosis [13].

Adiponectin regulates fat metabolism and insulin resistance. The adiponectin levels are low in obesity, insulin resistance and lipodystrophic syndrome [13]. Infusion of leptin and adiponectin can restore tissue insulin sensitivity, besides improving some aspects of lipodystrophy. In spite of these potential beneficial therapeutic aspects in adults, the effects in children have not been well studied [13].

\section{Mitochondrial Dysfunction}

Some studies show a connection between dyslipidemia, insulin resistance and lipoatrophy and an decrease of mitochondrial DNA in adipocytes [12,34]. Both HIV infection and NRTI affect mitochondrial DNA and function [12,34]. NRTI inhibit the DNA polymerase enzyme responsible for replicating mitochondrial DNA [47]. The intensity of this side effect is 
related to the level of dependence of an organ on mitochondrial function. Clinically they can cause lactic acidosis, hepatic steatosis, peripheral neuropathy, cardiomyopathy and pancreatitis [47]. Depletion of mitochondrial DNA of adipocytes contributes to the deterioration of subcutaneous fat, through the induction of metabolic dysfunction in adipocytes and cellular death [48].

\section{Treatment}

The main cause of morbidity and mortality in patients with lipodistrophy is the emergence of diabetes mellitus, recurrent episodes of acute pancreatitis, owing to high levels of triglycerides, cirrhosis secondary to hepatic steatosis and vascular atherosclerosis. In addition, some patients become psychologically affected due to non acceptance of their lipodystrophic appearance [49]. Several therapeutic options are available for correction of metabolic disorders and body fat composition, most of them proceeding from studies on adults. Nevertheless, there is still no totally effective management procedure. Table 1 summarizes the most common therapeutic alternatives.

\section{Antiretroviral Therapy Adjustment}

Lipodystrophic syndrome is more frequent in patients treated with PI, except for atazanavir, a new and potent PI not yet recommended for children [22,50]. Besides substituting traditional PI for atazanavir, other therapeutic options to attenuate dyslipidemia, insulin resistance and lipodistrophy include substitution of this PI with nevirapine (NNRTI), abacavir (NRTI), or efavirenz (NNRTI) [37,51]. Though there is little data concerning children, the substitution of PI therapy with efavirenz resulted in improvement of total cholesterol, LDL and triglyceride levels, while maintaining viral suppression [52]. This shows that it is possible to maintain HIV treatment without causing significant metabolic disorders, depending on the drug used.

\section{Diet and Exercise}

Low-fat diets and aerobic exercise are able to improve lipodystrophic and metabolic disorders [11,53]. However, caution with diabetic patients is advised so that a high-level carbohydrate diet, as a consequence of a low-fat diet, does not impair glycemia [11]. Association with metformin improves insulin levels, waist-hip ratio, blood pressure, muscular strength and transverse muscular area of the thigh [54-55]. However, since metformin causes weight loss, its use is not advised in patients with insulin resistance and lipoatrophy [37,54-55].

\section{Cosmetic Therapy}

One of the biggest problems faced by lipodystrophic syndrome patients is the esthetic result that comes from subcutaneous fat loss in the face, arms, legs and buttocks, and fat accumulation in the posterior neck and abdomen $[22,30]$. Facial lipoatrophy is the most frequent and stigmatizing manifestation. Its main psychological repercussions include low self-esteem and confidence, depression, anxiety, social isolation and lower quality of life [56]. In children and adolescents, the situation can become even more delicate due to greater higher psychological effects on this age group [6].

Lipohypertrophic lesions, with dorsocervical fat accumulation, can be treated with liposuction cosmetic surgery [37]. Unfortunately, there is no effective therapy for the management of lipoatrophic lesions [56]. Dermal filling with bovine collagen or highly purified silicone oil is limited [56]. Recently, poly-L-lactic acid (PLA) has given better results [56]. In Brazil, polymethyl methacrylate is the most widely disseminated facial filling substance, with its usage regulated by Brazilian Health Department judicial directive no. 2 of March 27, 2007.

\section{Insulin-Sensitizing Drugs}

Insulin-sensitizing drugs such as metformin and thiazolidinediones (rosiglitazone and pioglitazone) are recommended in the case of insulin resistance or diabetes mellitus [22,51]. These drugs improve body fat distribution [45]. The thiazolidinediones are indicated for lipoatrophic pattern problems, due to their unique effect in increasing subcutaneous and abdominal fat [57]. Metformin is counterindicated when there is a lipoatrophic presentation, due to its action in the reduction of body fat; its usage is indicated when there is a predominance of visceral obesity [37].

Other beneficial effects of the thiazolidinediones include: protection against the side effects of some PI, such as indinavir and nelfinavir [46], and reduction of the levels of the endothelium dysfunction serum markers $[22,58]$. However, the thiazolidinediones can cause an increase in liver enzymes and must not be used in patients with serum levels of alanine transaminase (ALT) higher than 2.5 times the normal range [45]. The concurrent use of metformin and NRTI antiretroviral drugs can cause lactic acidosis, thus requiring careful follow-up [22].

\section{Antihyperlipidemic Drugs}

Until now, there no concrete data concerning antihyperlipidemic therapy in HIV-infected children with dyslipidemia have been available. The therapeutic recommendations are, therefore, the same as are recommended to the general pediatric population [44]. In HIV-positive patients, it is important to be careful of a possible drug interaction between antiretroviral and antihyperlipidemic drugs [44]. Initial therapy should include a diet, maintaining vitamin intake and the quantity of calories necessary for normal growth and development, exercise, and risk factor control [6].

Pharmacological control of hypertriglyceridemia can be done with fibrates $[44,59]$. This drug class can be instituted along with PI, as its main metabolizing pathway is the CYP4A cytochrome, while the corresponding PI pathway is the CYP3A4 cytochrome [44]. Hypercholesterolemia can be treated with statins, which are HMG-CoA reductase inhibitors, if the usual precautions do not succeed. The statins simvastatin and lovastatin are counter-indicated as they are metabolized by the CYP3A4 cytochrome, which is inhibited by PI [6]. 
Table 1. Overview of therapeutic recommendations for HIV-associated lipodystrophic syndrome.

\begin{tabular}{|c|c|c|c|}
\hline \multirow[t]{2}{*}{ Suggested management } & \multicolumn{3}{|c|}{ Therapeutic action according to predominant clinical manifestation } \\
\hline & Lipoatrophy & Lipohypertrophy & Metabolic Syndrome \\
\hline Antiretroviral drugs & $\begin{array}{l}\text { Abacavir (NRTI) improves } \\
\text { peripheral fat loss }\end{array}$ & $\begin{array}{l}\text { Atazanavir (PI) } \\
\text { decreases dorsocervical } \\
\text { and abdominal fat }\end{array}$ & $\begin{array}{l}\text { Atazanavir (PI) decreases triglycerides } \\
\text { and cholesterol serum levels } \\
\text { Nevirapine and efavirenz improve total } \\
\text { cholesterol,LDL andtriglyceridesserumlevels }\end{array}$ \\
\hline Exercise & $\begin{array}{l}\text { Increase muscular strength } \\
\text { and transversal muscular } \\
\text { area of the thigh }\end{array}$ & $\begin{array}{l}\text { Decrease total body fat } \\
\text { and abdominal fat }\end{array}$ & $\begin{array}{l}\text { Decrease hyperlipidemia and insulin } \\
\text { resistance }\end{array}$ \\
\hline Diet & Without reported effects & Decreases total body fat & $\begin{array}{l}\text { Omega- } 3 \text { fatty acids with the aim of } \\
\text { reducing hypertriglyceridemia }\end{array}$ \\
\hline Lipid-lowering & Not indicated & Not indicated & $\begin{array}{l}\text { Indicated for children > } 10 \text { year-old with } \\
\text { LDL }>190 \mathrm{mg} / \mathrm{dL} \text {, or family history of } \\
\text { coronary disease. Alternate options: } \\
\text { Statins (pravastatin, rosuvastatin, } \\
\text { artovastatin), Ezetimibe, Fibrates. }\end{array}$ \\
\hline Insulin-sensitizing drugs & $\begin{array}{l}\text { Rosiglitazone increases } \\
\text { peripheral fat }\end{array}$ & $\begin{array}{l}\text { Metformin diminishes } \\
\text { body fat and abdominal } \\
\text { circumference }\end{array}$ & $\begin{array}{l}\text { Rosiglitazone and Metformin decrease } \\
\text { insulin resistance and fasting glucose } \\
\text { levels. Rosiglitazone reduces free fatty } \\
\text { acids and enhances adiponectin levels }\end{array}$ \\
\hline Growth hormone & Without clinical effect & $\begin{array}{l}\text { Decrease total body fat, } \\
\text { especially trunk adiposity }\end{array}$ & No clinical effect \\
\hline Cosmetic therapy & $\begin{array}{l}\text { Dermal filling with poly- } \\
\text { methyl methacrylate and } \\
\text { bovine collagen reduce } \\
\text { facial lipoatrophy }\end{array}$ & $\begin{array}{l}\text { Liposuction of } \\
\text { hypertrophic lesions }\end{array}$ & No clinical effect \\
\hline
\end{tabular}

The use of these drugs along with CYP3A4 inhibitors potentiate their toxic effects, such as myalgia, myopathy and rhabdomyolysis [6]. Three statins are currently recommended to patients on PI: pravastatin, rosuvastatin and artovastatin [44]. Among these, only the first has its use approved for children older than 10 years old, who maintain LDLc serum levels $\geq 190$ $\mathrm{mg} / \mathrm{dL}$, or $\geq 160 \mathrm{mg} / \mathrm{dL}$ after 6-12 months of diet modifications, with familial history of coronary artery disease, or when there are two other cardiac risk factors [6,59]. Another therapeutic option for hypercholesterolemia is the use of ezetimibe, a specific inhibitor of cholesterol absorption, preferably associated with pravastatin or rosuvastatin. Although the biliar acid sequestrating resins (cholestyramine and cholestipol) are approved for the treatment of hypercholesterolemia in children [59], they increase the triglyceride level and interfere in the absorption of antiretroviral drugs. Therefore, they are not recommended [6].

\section{Other Therapeutic Options}

\section{Growth Hormone}

The serum levels of growth hormone (GH) and insulin-like growth factor 1 (IGF-1) are decreased in some HIV-infected patients, in an inverse relationship with visceral fat accumulation [24,60-61]. Although it does not influence peripheral lipodistrophy and dyslipidemia, GH replacement improves trunk adiposity [37]. Its use is limited due to side effects, such as articular edema, liquid retention, insulin resistance and decreased glucose tolerance [11]. Vigano et al. adopted daily doses of $0.028 \mathrm{mg} / \mathrm{kg}$ of GH for 24 weeks, detecting an average reduction of $34.5 \%$ in the intra-abdominal adipose tissue, $10.4 \%$ in total body fat, and increased total lean mass [61]. Significant alterations in glucose metabolism or triglyceride and cholesterol levels were not detected. This shows a potential beneficial effect of GH in the treatment of LS [60]. Another study that used a GRF (growth hormone release factor) analog in lipodystrophic patients has shown that it results in benefits similar to those of GH [61].

\section{Testosterone}

A reduction in testosterone levels associated with visceral obesity and insulin resistance has been observed in HIVpositive men. Consequently, testosterone therapy has been prescribed in some situations in order to lower visceral fat and insulin resistance [51]. Compared to other anabolic steroids, nandrolone did not give a favorable outcome [11].

\section{Leptin}

Treatment with recombinant leptin is an alternate therapy for the future, as preliminary studies have shown improvement in glycemic control and decreased triglyceride levels in lipodystrophic and leptin deficiency patients [62]. 


\section{Clinical and Laboratorial Follow-Up}

The clinical evaluation includes a search for cardiovascular risk factors, weight measurement, height, body mass index, abdominal circumference, blood pressure and signs of body fat redistribution characteristic of lipodystrophy syndrome [37]. Lipid measurement before starting antiretroviral therapy should be done annually and each three to six months after beginning treatment or after any adjustment in the drug scheme [22,54]. The fasting plasma glucose level should be examined after institution of antiretroviral therapy or after alterations in the drug regimen, and annually in seropositive patients not using antiretroviral therapy. The oral glucose tolerance test and the fasting insulinemia dosage determination must be done in patients who present other risk factors for cardiovascular disease or who present a family history of type 2 diabetes mellitus [22]. Follow-up of liver function tests, including creatinine and creatine phosphokinase serum levels, is absolutely necessary when antihyperlipidemic drugs are introduced [22]. Hepatic dysfunction must be followed if thiazolinediones are prescribed, as along with lactate levels when metformin is instituted [54]. Though MRI, DEXA and CT are highly precise in measuring subcutaneous and visceral fat, they are not used in the medical follow-up of this disorder [54].

\section{Final Considerations}

The introduction of HAART reduced the mortality and progression of AIDS in HIV-infected patients. Nonetheless, prolonged use of antiretroviral therapy provokes the emergence of metabolic disorders, the morbidity of which has been increasing, especially due to an association with precocious cardiovascular disease. The changes in body fat distribution in HIV-infected patients can affect self-esteem and cause depression, affecting treatment adhesion. This is especially troublesome in adolescents. A better understanding of the pathophysiology of these metabolic disorders is important to help develop drugs with fewer side effects. Prospective studies are needed of HIV-infected children before and after therapy in order to determine the etiological and risk factors most involved in this disorder, as most of the studies and trials about this question have been made with adults.

\section{References}

1. Ortigão M.B. AIDS em crianças: considerações sobre a transmissão vertical. Cad Saúde Públ 1995;11:142-8.

2. Brito A.M., Sousa J.L., Luna C.F., Dourado I. Tendência da transmissão vertical de AIDS após terapia anti-retroviral no Brasil. Rev Saúde Pública 2006;40(Supl):18-22.

3. Szwarcwald C.L., Barbosa Júnior A., Fonseca M.G.P. Estimativa do número de crianças (0-14 anos) infectadas pelo HIV, Brasil, 2000. Boletim Epidemiológico-AIDS. Ano XV, $n^{\circ} 1,27^{\mathrm{a}}$ à $40^{\mathrm{a}}$ Semanas Epidemiológicas - julho a setembro de 2001.

4. Carr A., Samaras K., Burton S., Law M., et al. A syndrome of peripheral lipodystrophy, hyperlipidemia, and insulin resistance in patients receiving $\mathrm{HIV}-1$ protease inhibitors. AIDS 1998; 12 :F51-8.
5. Taylor P., Worrell C., Steinberg S.M., et al. Natural history of lipid abnormalities and fat redistribution among human immunodeficiency virus-infected children receiving long-term, protease inhibitor-containing, highly active antiretroviral therapy regimens. Pediatrics 2004;114:235-42.

6. McComsey G.A., Leonard E. Metabolic complications of HIV therapy in children. AIDS 2004;18:1753-68.

7. Bockhorst J.L., Ksseiry I., Toye M., et al. Evidence of human immunodeficiency vius-associated lipodystrophy syndrome in children treated with protease inhibitors. Pediatr Infect Dis J 2003;22:463-5.

8. Torres A.M.S., Muniz R.M., Madero R., et al. Prevalence of fat redistribution and metabolic disorders in human immunodeficiency virus-infected children. Eur J Pediatr 2005; 164:271-6.

9. European Paediatric Lipodystrophy Group. Antiretroviral therapy, fat redistribution and hyperlipidaemia in HIV-infected children in Europe. AIDS 2004;18:1443-51.

10. Martinez E., Mocroft A., García-Viejo M.A., et al. Risk of lipodystrophy in HIV-1-infected patients treated with protease inhibitors: a prospective cohort study. Lancet 2001;357:59298.

11. Chen D., Misra A., Garg A. Lipodystrophy in human immunodeficiency virus-infected patients. J Clin Endocrinol Metab 2002;87:4845-56.

12. Cossarizza A., Moyle G. Antiretroviral nucleoside and nucleotide analogues and mitochondria. AIDS 2004;18:137-51.

13. Krause J.C., Toye M.P., Stechenberg B.W., Reiter E.O., Allen H.F. HIV-associated lipodystrophy in children. Ped Endocrinol Rev 2005; $1: 45-51$.

14. Vigano A., Mora S., Testolin C., et al. Increased lipodystrophy is associated with increased exposure to highly active antiretroviral therapy in HIV-infected children. J Acquir Immune Defic Syndr 2003;32:482-9.

15. Vigano A., Giacomet V. Nucleoside analogues toxicities related to mitochondrial dysfunction: focus on HIV-infected children. In: Proceedings from the $1^{\text {st }}$ Meeting on mithochondrial toxicity \& HIV infection: understanding the pathogenesis for a therapeutic approach. 2005. Modena, Italy, May 19-21.

16. Amaya R.A., Kozinetz C.A., McMeans A., Schawarzald H., Kline M.W. Lipodystrophy syndrome in human immunodeficiency virus-infected children. Pediatric Infect Dis J 2002;21:405-10.

17. Bitnun A., Sochett E., Babyn P., et al. Serum lipids, glucose homeostasis and abdominal adipose tissue distribution in protease inhibitor-treated and naive HIV-infected children. AIDS 2003;17:1319-27.

18. Jaquet D., Lévine M., Ortega-Rodriguez E., et al. Clinical and metabolic presentation of the lipodystrophic syndrome in HIVinfected children. AIDS 2000;14:2123-8.

19. Temple M.E., Koranyi N., Nehata M.C. Lipodystrophy in HIVinfected pediatric patients receiving protease inhibitors. Ann Pharmacother 2003;37:1214-8.

20. Werner M.L.F. Alterações metabólicas e de distribuição da gordura corporal em crianças e adolescentes infectados pelo HIV/AIDS em uso de drogas antiretrovirais de alta potência [Master of Science thesis]; Rio de Janeiro: Instituto Fernandes Figueira; 2005.

21. Guimarães M.M., Greco D.B., Júnior A.R., Penido M.G., Machado L.J.C. Distribuição da gordura corporal e perfis lipidico e glicêmico de pacientes infectados pelo HIV. Arq Bras Endocrinol Metab 2007; $51: 42-51$.

22. Valente A.M.M, Reis A.F., Machado D.M., Succi R.C.M., Chacra A.R. Alterações metabólicas da síndrome lipodistrófica do HIV. Arq Bras Endocrinol Metab 2005;49:871-81.

23. Manfredi R., Calza L., Chiodo F. Gynecomastia, lipodystrophy syndrome, and dyslipidemia occurring or worsening during antiretroviral regimens other than protease inhibitor-based ones. J Acquir Immune Defic Syndr 2004;35:99-102. 
24. Vigano A., Mora S., Brambilla P., et al. Impaired growth hormone secretion correlates with visceral adiposity in highly active antiretroviral treated HIV-infected adolescents. AIDS 2003; 17:1435-41.

25. Hartman K., Verweel G., de Groot R., Hartwig N.G. Detection of lipoatrophy in human immunodeficiency virus-1-infected children treated with highly active antiretroviral therapy. Pediatr Infect Dis J 2006;25:427-31.

26. Brambilla P., Bricalli D., Sala N., et al. Highly active antiretroviraltreated HIV-infected children show fat distribution changes even in absence of lipodystrophy. AIDS 2001;15:2415-22.

27. Beregszaszi M., Dollfus C., Levine M., et al. Longitudinal evaluation and risk factors of lipodystrophy and associated metabolic changes in HIV-infected children. J Acquir Immune Defic Syndr 2005;40:161-8.

28. Farley J., Gona P., Crain M., Cervia J., et al; Pediatric AIDS Clinical Trials Group Study 219C Team. Prevalence of elevated cholesterol and associated risk factors among perinatally HIV-infected children (4-19 years old) in Pediatric AIDS Clinical Trials Group 219C. J Acquir Immune Defic Syndr 2005;38:480-7.

29. Cheseaux J.J., Jotterand V., Aebi C., et al. Hyperlipidemia in HIVinfected children treated with protease inhibitors: relevance for cardiovascular diseases. J Acquir Immune Defic Syndr 2002;30:288-93.

30. Valente O., Valente A.M.M. Síndrome lipodistrófica do HIV: um novo desafio para o endocrinologista. Arq Bras Endocrinol Metab 2007;51:3-4.

31. Bitnun A., Sochett E., Dick P.T., et al. Insulin sensitivity and betacell function in protease inhibitor-treated and -naive human immunodeficiency virus-infected children. J Clin Endocrinol Metab 2005; 90:168-74.

32. Brandão A.P., Brandão A.A., Berenson G.S., Fuster V. Metabolic syndrome in children and adolescents. Arq Bras Cardiol 2005; 85:79-81.

33. Grundy S.M., Brewer B., Cleeman J.I., Smith S.C., Lenfant C. Definition of metabolic syndrome. Report of the National Heart, Lung, and Blood Institute/ American Heart Association Conference on Scientific Issues related to definition. Circulation 2004;109:433-8.

34. Cossarizza A., Pinti M., Moretti L., et al. Mitochondrial functionality and mitochondrial DNA content in lymphocytes of vertically infected human immunodeficiency virus-positive children with highly active antiretroviral therapy-related lipodystrophy. J Infect Dis 2002;185:299-305.

35. Desai N., Mathur M., Weedon J. Lactate levels in children with HIV/AIDS on highly active antiretroviral therapy. AIDS 2003;17:1565-8.

36. Berenson G.S., Srinivasan S.R., Bao W., et al., For The Bogalusa Heart Study. Association between multiple cardiovascular risk factors and atherosclerosis in children and young adults. N Engl J Med 1998;338:1650-6.

37. Grinspoon S., Carr A. Cardiovascular risk and body-fat abnormalities in HIV-infected adults. N Engl J Med 2005;352:48-62.

38. Charakida M., Donald A.E., Green H., et al. Early structural and functional changes of the vasculature in HIV-infected children: impact of disease and antiretroviral therapy. Circulation 2005;112:103-109

39. The DAD Study Group. Cardio- and cerebrovascular events in HIV-infected persons. AIDS 2004;18:1811-7.

40. The Data Collection on Adverse Events of Anti-HIV Drugs (DAD) Study Group. Combination antiretroviral therapy and the risk of myocardial infarction. N Engl J Med 2003;349:1993-2003.

41. Mary-Krause M., Cotte L., Simon A., et al. Increased risk of myocardial infarction with duration of protease inhibitor therapy in HIV-infected men. AIDS 2003;17:2479-86.

42. Bozzette S.A., Ake C.F., Tam H.K., et al. Cardiovascular and cerebrovascular events in patients treated for human immunodeficiency virus infection. N Engl J Med 2003;348:702-10.
43. Lipshultz S.E., Kirk A., Easley M.S., et al. Absence of cardiac toxicity of zidovudine in infants. Pediatric pulmonary and cardiac complications of vertically transmitted HIV Infection Study Group. N Engl J Med 2000;343:759-66.

44. Yu P.C., Calderaro D., Lima E.M., Caramelli B. Hypolipidemic therapy under special conditions: acquired immune deficiency syndrome. Arq Bras Cardiol.2005;85:58-61.

45. Castelo Filho A., Abrão P. Alterações metabólicas do paciente infectado por HIV. Arq Bras Endocrinol Metab 2007;51:5-7.

46. Caron M., Auclair M., Sterlingot H., et al. Some HIV protease inhibitors alter lamin A/C maturation and stability, SREBP-1 nuclear localization and adipocyte differentiation. AIDS 2003; $17: 2437-44$.

47. Hoschele D. Cell culture models for the investigation of NRTIinduced mitochondrial toxicity. Relevance for the prediction of clinical toxicity. Rev Toxicol in Vitro 2006;20:535-46.

48. Nolan D., Hammond E., Martin A., et al. Mitochondrial DNA depletion and morphologic changes in adipocytes associated with nucleoside reverse transcriptase inhibitor therapy. AIDS 2003; $17: 1329-38$.

49. Garg A. Acquired and inherited lipodystrophies. N Engl J Med 2004;350:1220-34

50. Haerter G., Manfras B.J., Mueller P.K., Trein A. Regression of lipodystrophy in HIV-infected patients under therapy with the new protease inhibitor atazanavir. AIDS 2004;18:952-5.

51. Schambelan M., Benson C.A., Carr A., et al. Management of metabolic complications associated with antiretroviral therapy for HIV-1 infection: Recommendations of an International AIDS Society-USA Panel. JAIDS J Acquir Immune Defic Syndr 2002;31:257-75.

52. McComsey G., Bhumbra N., Ma J.F., et al. Impact of protease inhibitor substitution with efavirenz in HIV-infected children: results of the first pediatric switch study. Pediatrics 2003;111:e275-e81.

53. Roubenoff R., Schmitz H., Bairos L., et al. Reduction of abdominal obesity in lipodystrophy associated with human immunodeficiency virus infection by means of diet and exercice: case report and proof of principle. Clin Infect Dis 2002;34:390-3.

54. Driscoll S.D., Meininger G.E., Lareau M.T., et al. Effects of exercise training and metformin on body composition and cardiovascular indices in HIV-infected patients. AIDS 2004;18:465-473.

55. Driscoll S.D., Meininger G.E., Ljungquist K., et al. Differential effects of metformin and exercise on muscle adiposity and metabolic indices in human immunodeficiency virus-infected patients. J Clin Endocrinol Metab 2004;89:2171-8.

56. Treacy P.J., Goldberg D.J. Use of a biopolymer polyalkylimide filler for facial lipodystrophy in HIV-positive patients undergoing treatment with antiretroviral drugs. Dermatol Surg2006;32:804-8.

57. van Wijk J.P.H., Koning E.J.P., Cabezas M.C., et al. Comparison of rosiglitazone and metformin for treating HIV lipodystrophy. Ann Intern Med 2005;143:337-46.

58. Hadigan C., Rabe J., Grinspoon S. Sustained benefits of metformin therapy on markers of cardiovascular risk in human immunodeficiency virus-infected patients with fat redistribution and insulin resistance. J Clin Endocrinol Metab 2002;87:4611-5.

59. Consenso Brasileiro sobre Dislipidemias. Arq Bras Cardiol 2005; 85(Supl VI):1-36

60. Vigano A., Mora S., Manzoni P., et al. Effects of recombinant growth hormone on visceral fat accumulation: pilot study in human immunodeficiency virus-infected adolescents. J Clin Endocrinol Metab 2005;90:4075-80.

61. Falutz J., Allas S., Kotler D., et al. A placebo-controlled, doseranging study of a growth hormone releasing factor in HIVinfected patients with abdominal fat accumulation. AIDS 2005;19:1279-87.

62. Oral E.A., Simha V., Ruiz E., et al. Leptin-replacement therapy for lipodystrophy. N Engl J Med 2002;346: 570-8. 